\section{Trends and priorities in internal audit}

Victoria STANCIU, Bucharest University of Economic Studies, E-mail: victoria.stanciu@cig.ase.ro

\section{Alsstract}

The status of the internal audit as an important pillar for corporate governance is recognized unanimously; however, this status is gained through a continuous and joined effort of all internal auditors and by a clear and solid vision of the internal audit function's development, designed by the chief of internal audit. This status recognizes the internal audit's support for the achievement of company objectives and the improvement of risk management and it also requires continuous quantitative accumulations in the work of internal auditors. From this perspective, the author's attention focused on the main risks and priorities that the internal audit is facing as they are reflected by international studies and surveys. The conclusions emphasized by the author's research may be considered important milestones for the improvement of the internal audit function in Romania and for its solid connection to the realities and problems the companies are confronting with.

Keywords: Internal audit, risk assessment, performance, audit plan.

JEL Classification: M42, M15, 033.

\section{To cite this article:}

Stanciu, V. (2016), Trends and priorities in internal audit, Audit Financiar, vol. XIV, no. 9(141)/2016, pp. 1003-1008, DOI: 10.20869/AUDITF/2016/141/1003

To link to this article:

http://dx.doi.org/10.20869/AUDITF/2016/141/1003 


\section{Introduction}

Internal audit $(I A)$ is an important pillar for the corporate governance. However, this status is not obtained by itself; on the contrary, it results from a joined effort of the entire IA department and by a clear vision provided by the chief of internal audit (CAE). The competition on the internal market and especially in the global economy generates increased concerns regarding the companies' financial performance. Achieving the business objectives and financial performance remains a major concern for decision-makers and it also represents the investigation space for IA, whose role is to support the company in the achievement of its objectives by an efficient use of resources and the improvement of business and risk management processes.

The studies emphasized that the maturity level of the IA function differs from one country to another, a fact explained by cultural differences and the IA functions' "age", the economic development being also a determinant factor. Corporate governance has its own impact on the development of the IA function (Sarens et al., 2011). In Romania, the IA function is implemented for more than a decade, a fact that can explain the relatively reduced maturity level as compared to the one registered in western countries. The difficulties that are still manifesting in the process of solid corporate governance implementation have influenced the consolidation effort of IA function in Romanian companies. Romanian internal auditors have the advantage to learn from the experience of other countries and benefit from the progress registered in the profession as a result of the joined efforts of international professional organizations.

The present paper aims to emphasize the tendencies and priorities of IA as they are reflected by the international studies issued in the last years. The author considers that emphasizing these aspects is extremely useful for the Romanian internal auditors, helping them to better plan their missions, to improve their working methods and their own professional abilities, and to consolidate the collaboration with the audit committee members and executive management.

\section{Research methodology}

The performed research is a qualitative one. The followed objectives are the identification of the trends, priorities, objectives, and techniques used in IA worldwide, aiming to provide comparative information related to the IA characteristics in Romania. The research required a review of IA literature worldwide, as well as the analysis of studies carried out by prestigious international organizations regarding the evolution of IA. The present research is part of a wider research project meant to cover a large timeframe, which was initiated several years ago and is aiming at tracking the evolution of IA in Romania and the implementation of best practices, while promoting IT-based methodologies and techniques.

\section{Priorities in internal audit}

The risk-oriented approach has become a constant for IA. The entire activity performed by internal auditors is determined by the risks that company is exposed to. Knowing the particularities of the business and industry the company is operating in, internal auditors must identify the strategic risks and current operations and, at the same time, anticipate the main strategic risks for the future. Therefore, internal auditors must anticipate those risk exposures, monitor the existing risks and establish the audit plan and missions' objectives based on the estimated risk exposures. The annual plans will reflect the stakeholders' expectations (expressed or anticipated by internal auditors) and the estimated risks trends that could deter the achievement of companies' objectives. It is necessary to underline the importance of anticipation in IA work, but also to emphasize the proactive character of the internal auditors' work. If internal auditors, by their arguments, will convince the audit committee that the annual plan focuses on key risks that affect the business, they will obtain not only the approval for the IA plan, but also the required budget for its implementation and the entire support they need to perform their mission.

Recent international studies emphasize the need that internal auditors turn their attention to the risks generated by the rapid development of technology, with significant impact over the business processes, a special place being allocated to the information technology (IT) and the risks associated with its employment. From this perspective, the internal auditors need to assess the "likely impact of possible future events - including their second and third order consequences - on their organizations' strategies and operations" (Harrington 
and Piper, 2016). This implies, on the one hand, increased abilities of internal auditors related to the specificity of audit missions regarding information systems and computerized data processing and transmission, and, on the other hand, the assessment of the specific risks, by taking into consideration not only their direct impact, but the entire chain of consequences. The occurrence of some IT risks might produce as a direct consequence data security breaks and/or impairment of data processing quality - including possible systems' cut-off (hackers' attacks, viruses attacks). Secondly, IT risks might induce financial losses as a result of the business processes cut-off (the information systems supporting them being inoperable). As a third order consequence, IT risks might generate data leakages for the benefit of competitors, determining the loss of business opportunities or the decrease of the market share.

The IT risk is among the first five risks the internal auditors are concerned with. From the managers' perspective, the risks involving the highest attention are the operational risks, business strategic risks and compliance risk. Nevertheless, one of five internal auditors state that they spend no time auditing the company's information security, while one of four internal auditors declare that they do not allocate any time to auditing social media (Harrington and Piper, 2016). This fact is explained by the specific competencies required for information systems' audit activities and by the low number of auditors who have a bachelors' degree in computing or who are certified as IT auditors. Therefore, sensitive aspects are represented by the continuous training of internal auditors focusing on information technology and also the need for the university training of accountants to be more oriented towards IT audit. We refer to the accounting university studies, taking into consideration that, significantly, accounting bachelors are more oriented towards the IA profession, accounting being the expertize area asked especially in the recruitment and continuous training processes.

For the banking and financial markets industry, the internal auditors' attention is focused on (KPMG, 2016):

- Increasing regulatory expectations;

- Culture and conduct;

- Regulatory reporting;

- Stress tests;
- Cybersecurity;

- Third party relationships management (as a result of outsourcing some activities and the IT systems maintenance services);

- Continuous risk assessment;

- Data analysis/continuous audit;

- Recruitment and retention of experienced professionals.

A priority for IA is represented by the extended use of IT in the auditors' work. Four of ten CAEs declare that "the use of technology is appropriate or better" - comparing with 2006 - when the previous survey took place (Cangemi, 2015). The same survey emphasized that two of ten CAEs declare that "their departments primarily rely on manual techniques". This fact could be determined by:

- The level of knowledge and abilities internal auditors have in the field of IT;

- The insufficient budgets allocated to the IA function making difficult or actually impossible the acquisition of IT-dedicated software; and

- The inadequate strategy on IA development based on IT-dedicated instruments ensuring efficiency and effectiveness to IA.

Among the IT instruments and products which can be used by internal auditors we mention:

- Electronic work papers;

- Automated tools to manage the information collected;

- Instruments for data analysis;

- Tools for data mining;

- Tools for continuous audit;

- Instruments for planning audit missions;

- Instruments for IA follow-up activities;

- Software for risk assessment etc.

By emphasizing the need to focus internal auditors' attention on IT risks, the mentioned surveys confirm the findings from previous studies (such as Protiviti, 2014) that underlined as priorities for IA:

- Social media, applications using mobile devices, cloud computing, information security;

- Use of Computer Assisted Audit Techniques CAATs and data analysis tools; 
- Fraud prevention and identification, based on technology.

Protiviti (2016) continued the survey in 2016 emphasizing that the cybersecurity risk is constantly included in the audit plan and important priorities are registered in regard with the use of mobile devices, cloud computing, IT standards and Internet of Things (Protiviti, 2016).

The data mining tools usage registered a moderate increase, the majority of the respondents declaring their use at the basic level. Data mining can be used successfully to identify fraud and anomalies in commercial activities, data shortages/inconsistency, risk monitoring etc. It is important to underline that data mining and data analysis processes are partially performed in IA departments. In Europe, for example, $18 \%$ of those processes are performed outside the IA departments (Cangeni, 2015). Including data analysis in the specific working processes of internal auditors will ensure the increase of the efficiency and effectiveness of their work, one of the vectors being the continuous risk assessment process performed in this context.

\section{Professional competencies and abilities}

The internal auditors' professional profile registers a constant dynamic as a result of the evolution in the accounting profession, as a general framework, and of changes in the business and regulatory environments. These changes involve an in-depth knowledge of business models, processes and activities performed within a company, many of which are IT-based and as a result require IT abilities and skills. Henderson, Davis and Lapke (2013) underline the tight connection between the business processes and IT, the entire infrastructure of the company being IT-based. This fact determines changes in the IA and the established objectives, activities carried out and the knowledge required from the auditors.

The IA resources, in terms of the number of certified internal auditors, are limited, the concern to retain/recruit specialists is high, a lot of researches aiming at identifying the knowledge and abilities required from internal auditors. As a result, there were identified specific requirements regarding abilities and knowledge related specifically to the professional profile, and also an extended set of abilities related to the relationship and communication skills, which are extremely important for an internal auditor.

Among the abilities asked from the auditors we mention: public speaking, time management (useful in the establishment of audit plans and the management of missions), building solid relationships with the IA committee members, executive management and external contacts, the ability to face high pressure meetings, leadership, strategic thinking etc.

Harrington and Piper (2016) emphasize that the main knowledge, abilities and competencies asked for the internal auditors are:

- Critical thinking;

- Communication skills;

- Accounting;

- Risk management assurance;

- Information technology (general knowledge);

- Industry specifics.

It is not surprising that the answers to questionnaires placed critical thinking on the first place. The entire work of an internal auditor is based on this critical thinking, starting from the identification of the critical areas to be audited as a result of the risk assessment, the selection of audit procedures and ending with the opinion and recommendations. Communication is essential, helping internal auditors to identify the stakeholders' expectations, to build strong relationships with the IA committee members and managers, gaining their trust and their support in solving problems. Communication is also necessary during missions when, based on questionnaires or in interviews, the auditors collect the necessary information. On the third place there is placed the accounting knowledge, which, in most cases, represents the professional background of the internal auditors. The IT knowledge has an important place, as a result of the IT-based environment in which the company operates, and as a result of the extended use of IT instruments by the internal auditors in their daily activities.

\section{Measuring internal audit performance}

Maybe one of the most sensitive problems, less investigated by the researchers, is the way in which IA performance is measured. The topic is of special interest 
for both scientists and IA professionals, as well as for companies. How are the quality of $I A$ activities and the adequacy to stakeholders' needs and expectations assessed? An insight into the practice of the profession would emphasize the interest for the question showed by the CAEs and their entire teams, and also by the audit committee and executives.

The practice guide issued by the Institute of Internal Auditors - IIA underlines that "IA should establish performance metrics and related measurement criteria appropriate to its environment/organization to measure the degree (including quality) of achievement of objectives for which the IA activity is established" (IIA, 2010).

The practice of IA led the way to the establishment of a set of metrics, mainly quantitative, such as, for example:

- Planned vs. completed audit missions according to the approved audit plan;

- Proper use of budgets;

- Performance of audit mission in the allocated time budget;

- Time for issuing the audit report;

- The degree to which recommendations made as a result of completed IA missions were accepted and implemented;

- Cost savings and/or income increase as a result of IA recommendations for the improvement of processes and activities.

In our opinion, the IA evaluation should emphasize the way in which the IA helped the organization to achieve its objectives. The last two indicators mentioned above are adequate in this regard.

The IIA (2010) recommends to include between the criteria used for the assessment of IA, next to the ones mentioned above, the following items:

- The total number of annual training hours per auditor;

- The internal auditors' experience, including the number of certified internal auditors, their expertize etc.;

- The use of the internal auditors' time - direct vs. indirect time used;

- Staff retention/Turnover in the IA department;

- Average response time to the stakeholders' requirements;
- The quality of the feedback from auditees (the number of positive vs. negative ones);

- The usage of new information technologies in IA activities.

Aiming at adding value and contribute, in a direct way, to the financial performance of the company, IA should offer solutions for the improvement of processes and the identification of business opportunities. The number of recommendations for cost savings, processes improvements (including an improved risk management), recommendations for a better use of resources, identification of business opportunities, recommendations for an improved alignment to the compliance issues could all represent criteria for the evaluation of IA, close to the stakeholders' expectations. By the nature of the missions and objectives established, IA should be aligned to the company's priorities aiming at achieving the business objectives. Nevertheless, the study by Harrington and Piper (2016) emphasizes that $57 \%$ of the respondents declare that they are "totally or mostly aligned to the business strategic plan". Under these conditions, the objective of IA to support the company in achieving its objectives is difficult to fulfil.

As the risks' evolution registers a constant dynamic, the updating of annual audit plans (by changing the missions' prioritization as well as including new ones as a result of increased risk exposure) could be considered as a useful criterion in assessing IA. This type of changes, argued in front of audit committee, prove the quality of the risk assessment process performed by internal auditors and the focus of missions on the most risk exposed areas.

\section{Conclusions}

IA registers a continuous evolution determined by the dynamic environment that it is asked to investigate, the expectations - always changing - expressed by stakeholders and, not the least, by the requirements of best practice specific for IA. The quality of the results is mainly determined by the way internal auditors succeed to anticipate correctly the risk evolution and the requirements of audit committee and executives, focusing on the most risk-exposed areas and offering the recommendations for the improvement off processes and the achievement of strategic objectives. 
Highly priority items in the internal auditors' work are: the alignment to the company's strategic business risks, the rigorous approach of the IT risks by their integration with the business risks, the assimilation of the IT-based techniques and instruments in the current activity, the recruitment of experienced auditors proving extended computer skills, and the continuous training, including in the IT field.
Establishing metrics for the IA assessment altogether with the approval of the IA plan, and the permanent monitoring of their values by the CAE and audit committee offer objective criteria to assess and connect the audit work to the company's performance. These aspects also contribute to the fulfilment of requirement that the IA's support the company in achieving its objectives.

\section{REFERENCES}

1. Cangemi, M. (2015), Staying a Step Ahead Internal Audit's Use of Technology, [pdf] Available at: www.internerevision.at/fileadmin/user_upload/20151403_CBOK_Staying_A_Step_Ahead.pdf [Accessed on July 22, 2016].

2. Harrington, L. and Piper, A. (2016), Driving Success in a Changing World: 10 Imperatives for Internal Audit, [pdf] Available at: http://www.aair.ro/fisiere/ PIPER_Ten_Imperatives_Final.pdf, [Accessed on July 22, 2016].

3. Henderson, D., Davis, J. and Lapke, M. (2013), The Effect of Internal Auditors' Information Technology Knowledge on Integrated Internal Audits, International Business Research, vol. 6, no. 4, pp. 147-163, DOI: http://dx.doi.org/10.5539/ibr.v6n4p147.

4. KPMG (2016), Internal Audit Top 10 Key Risks in 2016. Banking and Capital Markets, [pdf] Available at: https://www.kpmg.com/AE/en/Documents/ 2015/KPMGThoughtLeadership/KPMGInternalAuditT op10risksin2016.pdf, [Accessed on July 22, 2016].

5. IIA (2010), IPPF - Practice Guide. Measuring Internal Audit Effectiveness, [pdf] Available at: http://iia.nl/SiteFiles/IIA_leden/Praktijkgidsen/Practic e\%20guide $\% 20$ Measuring $\% 20$ Internal\%20Audit $\% 20$ Effectiveness.pdf, [Accessed on July 22, 2016].

6. Protiviti (2014), Assessing the Top Priorities for Internal Audit Functions. 2014 Internal Audit Capabilities and Needs Survey, [pdf] Available at: https://www.protiviti.com/enUS/Documents/Surveys/2014-Internal-AuditCapabilities-and-Needs-Survey-Protiviti.pdf, [Accessed on July 22, 2016].

7. Protiviti (2016), Arriving at Internal Audit's Tipping Point Amid Business Transformation. Assessing the Results of the 2016 Internal Audit Capabilities and Needs Survey - and a Look at Key Trends over the Past Decade, [pdf] Available at: https://www.protiviti. com/enUS/Documents/Surveys/2016-Internal-AuditCapabilities-and-Needs-Survey-Protiviti.pdf, [Accessed on July 22, 2016].

8. Sarens G., Allegrini, M., D'Onza, G. and Melviole, R. (2011), Are Internal Auditing Practices Related to the Age of Internal Audit Function? Exploratory Evidence and Directions for Future Research, Managerial Auditing Journal, vol. 26, no. 1, pp. 51-64, DOl: http://dx.doi.org/10.1108/02686901111090835. 